\title{
Convergent but Temporally Separated Inputs to Lateral Amygdala Neurons from the Auditory Thalamus and Auditory Cortex Use Different Postsynaptic Receptors: In Vivo Intracellular and Extracellular Recordings in Fear Conditioning Pathways
}

\author{
Xing Fang Li, Grace E. Stutzmann, and Joseph E. LeDoux ${ }^{1}$
}

Center for Neural Science

New York University

New York, New York 10003

\section{Abstract}

The lateral nucleus of the amygdala (LA), a key component of the fear conditioning circuitry, receives a rapid but relatively impoverished auditory input from the auditory thalamus and a slower but richer input from the auditory cortex. We examined in urethane anesthetized rats whether individual cells in the $L A$ receive convergent inputs from these two areas, and whether different postsynaptic receptors contribute to the temporally separated excitations over the two pathways. With both extracellular and intracellular recordings, individual cells could be activated by stimulation of each pathway. In extracellular recordings iontophoretic application of the $\boldsymbol{N}$-methyl-D-aspartate (NMDA) receptor antagonist APV and the L- $\alpha$-amino-3-hydroxy-5-methyl-4-isoxazole propionate (AMPA) receptor antagonist CNQX demonstrated that synaptic transmission in both pathways depends on AMPA receptors, whereas transmission in the thalamic pathway also depends on the involvement of NMDA receptors. The involvement of NMDA receptors in synaptic activation of the LA from the thalamus but not the cortex was confirmed in intracellular recordings

${ }^{1}$ Corresponding author. using systemic injections of the NMDA antagonist MK-801. The slow time course of NMDA currents could provide LA cells with a mechanism to integrate the inputs arriving rapidly from the thalamus and somewhat later from the cortex, thus allowing the LA to integrate signals in the two pathways during the acquisition and expression of conditioned fear reactions.

\section{Introduction}

The lateral nucleus of the amygdala (LA) is an essential component of the neural system through which external stimuli are endowed with emotional significance as a consequence of aversive experiences, and may in fact be a crucial site of plasticity during such experiences (Davis et al. 1994; LeDoux 1995; Maren and Fanselow 1995; Rogan and LeDoux 1996). Lesions of the LA interfere with the conditioning of fear reactions to a tone paired with footshock (LeDoux et al. 1990a; Campeau and Davis 1995); individual cells in the LA are responsive to both tones and footshocks (Romanski et al. 1993); and the responsivity of LA cells to tones is modified both by high-frequency tetanization of auditory input pathways (Rogan and LeDoux 1995) and by temporal pairing of tones with footshocks (Quirk et al. 1995). In addition, blockade of $N$-methyl-D-aspartate (NMDA) receptors in the LA and the underlying basal nu-

LEARNING \& MEMORY 3:229-242 @ 1996 by Cold Spring Harbor Laboratory Press ISSN1072-0502/96 $\$ 5.00$

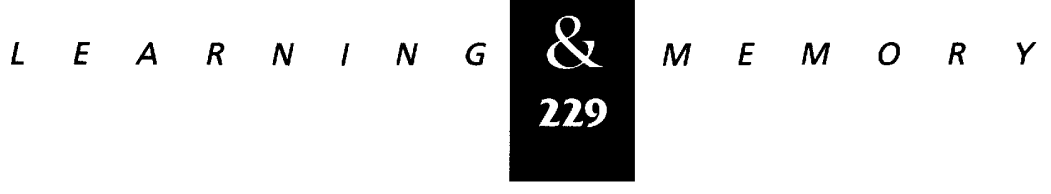


Li et al.

Figure 1: (A) Pathways of auditory transmission to the lateral nucleus of the amygdala (LA). Auditory information received peripherally is transmitted through the brainstem auditory pathways and ultimately to the medial geniculate body (MGB). The tonotopically organized ventral nucleus of the MGB (MGV) projects to the primary auditory cortex (TE1), which in turn projects to the auditory association cortex (TE3). TE3 is the major source of auditory input to the LA (although the perirhinal cortex, which projects to the LA and other amygdala nuclei, may also function in part as an auditory association region). The LA also receives auditory inputs from the medial division of the MGB (MGm) and the adjacent posterior intralaminar nucleus (PIN). These areas are part of the extralemniscal auditory system and contain cells that are broadly tuned (the MGm and PIN also project to the TE1 and TE3). The thalamo-amygdala pathway is thus shorter and faster than the cortico-amygdala route, but it provides the LA with a weaker representation of the auditory stimulus. $(B)$ Procedures used to determine whether individual cells in the LA receive convergent input from the auditory thalamus and cortex. Bipolar stimulating electrodes were placed in the MGm/PIN and TE3, and a recording electrode lowered into the LA. In extracellular recordings, stimulation of the afferent fibers resulted in evoked action potentials. The use of intracellular recordings allowed for measurement of more subtle membrane potential changes such as EPSPs and IPSPs.

cleus interferes with fear conditioning (Miserendino et al. 1990; Fanselow and Kim 1994). This is significant because NMDA receptors are known to be involved in experience-dependent plasticity in some brain pathways (Brown et al. 1988; Malenka and Nicoll 1993; Collingridge and Bliss 1995).

Auditory signals reach the LA by way of two pathways (LeDoux 1986; 1995). One involves direct transmission from auditory processing regions in the thalamus, and the other involves projections from the auditory thalamus to the auditory cortex, and from there to the LA (Fig. 1A). Transmission from the thalamus to the LA involves a monosynaptic projection (LeDoux et al. 1990b, 1991a,b; LeDoux and Farb 1991; Bordi and LeDoux 1994a,b), whereas transmission over the cortical pathway involves projections from the thalamus to the cortex, intracortical connections, and projections from the cortex to the LA (LeDoux et al. 1991a; Romanski and LeDoux $1993 a, b)$. The thalamic projection originates in cells that have relatively weak tuning properties (Bordi and LeDoux 1994a,b), whereas the cortical projection originates in auditory association areas
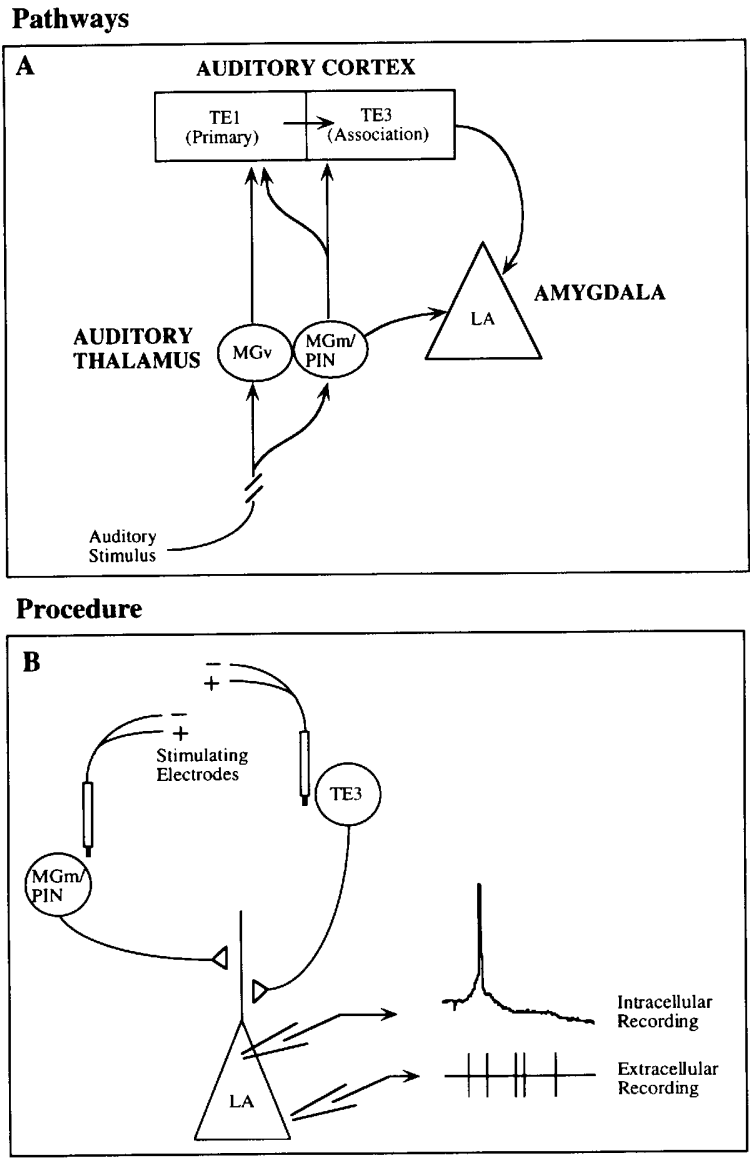

and can potentially send highly processed auditory information to the LA (Turner et al. 1980; Amaral et al. 1992; Mascagni et al. 1993; Romanski and LeDoux 1993b). The thalamic pathway is thus believed to provide the LA with rapid but impoverished stimulus information, whereas the cortical pathway has more synaptic links and is slower, but provides a more detailed representation (LeDoux 1986, 1995). Although the cortical input provides I.A with more information about the exact nature of the stimulus, the thalamic pathway may allow the amygdala to rapidly initiate defense responses to potentially dangerous stimuli on the basis of a crude analysis of stimulus features.

We hypothesize that one function of the LA is to integrate auditory information arriving from the thalamus and cortex during the acquisition and storage of conditioned associations, as well as during the expression of conditioned responses. As an initial test of this hypothesis we examined whether individual cells receive inputs from both areas (Fig. 1B). To do this, we recorded unit responses in the LA elicited by stimulation of the auditory thalamus and auditory cortex in anesthe- 
tized rats. Both extracellular and intracellular recordings were conducted in vivo. After finding evidence for convergence of the two auditory pathways onto single LA cells, we determined whether different receptor mechanisms are used to produce the temporally separated excitations of individual neurons. The results not only provide evidence for convergence but also suggest a physiological mechanism that might mediate the temporal integration.

\section{Materials and Methods}

Experiments were performed on adult male Sprague-Dawley rats weighing $250-350 \mathrm{~g}$. The anesthetic, surgical, and recording procedures were carried out as described previously ( $\mathrm{Li}$ et al. 1995). Briefly, the animals were anesthetized with urethane $(1.6 \mathrm{~g} / \mathrm{kg}$, i.p. $)$ and placed in a stereotaxic frame. Body temperature was maintained at $\sim 37^{\circ} \mathrm{C}$ with a heating pad. Depth of anesthesia was monitored by frequently testing reflex responses elicited by pinching the tail with forceps. A single dose of urethane was typically sufficient to maintain anesthesia throughout the course of the experiment, which usually lasted $\sim 5-7$ hours. Occasionally, additional doses of urethane were required and were applied.

The cranium above the medial geniculate body (MGB), auditory cortex, and the LA was exposed and the dura retracted, as described in previous publications (Clugnet et al. 1990; Bordi and LeDoux 1992). Electrodes (see below) were then inserted into the MGB and auditory cortex for stimulation of fibers projecting to LA, and a recording electrode placed in the the LA for extracellular recording of single unit responses and intracellular recording. The stimulating electrodes were stereotaxically targeted for the intersection of the medial division of the MGB (MGm) and the posterior intralaminar nucleus (PIN), and the auditory association cortex (TE3). These areas account for most of the auditory projections from the thalamus to the amygdala and from the auditory cortex to the amygdala. (LeDoux et al. 1991a; Romanski and LeDoux 1993b; Bordi and LeDoux 1994a,b).

The MGB and the auditory cortex stimulating electrodes were inserted at a $10^{\circ}$ angle, relative to the anterior-posterior plane, to allow sufficient room for positioning the various electrodes in the desired locations. The stimulating electrodes were advanced through the brain manually until the desired stereotaxic coordinates were reached (MGB: anterior $3.8 \mathrm{~mm}$, medial $3.0 \mathrm{~mm}$ relative to the interaural line, ventral $6.1 \mathrm{~mm}$ relative to the brain surface; auditory cortex: anterior $4.0 \mathrm{~mm}$, medial $6.9 \mathrm{~mm}$ relative to the interaural line, ventral 3.1 $\mathrm{mm}$ relative to the brain surface). The MGB and auditory cortex were stimulated with single pulses $(100-500 \mathrm{~mA} ; 0.2-1.0 \mathrm{~Hz} ; 100-500 \mu \mathrm{sec})$ produced from a Grass $\$ 88$ constant-current stimulator. Stimuli were delivered through a bipolar concentric stimulating electrode $(R=30-40 \mathrm{k} \Omega)$. Stimulation placements were identified histologically by the location of the tip electrode track (which was usually clearly visible) or by passing current through the stimulating electrode (100 $\mu \mathrm{A}$ DC, $10 \mathrm{sec}$ ).

Extracellular single-unit recordings were made using a multibarrel electrode assembly. The fabrication of these electrodes has been described in detail elsewhere ( $\mathrm{Li}$ et al. 1995). In brief, a fivebarrel micropipette (10-20 $\mu \mathrm{m}$ tip diameter) was glued adjacent to a single-barrel micropipette with a light-curing dental fixative ( $3 \mathrm{M}$ Silux). The tip of the single barrel pipette extended 12-35 $\mu \mathrm{m}$ beyond the tip of the five-barrel array. Extracellular recordings from individual neurons were obtained from the single barrel glass micropipette (1-3 $\mu \mathrm{m}$ tip diameter, 10-20 M $\Omega$ impedance) filled with $2.5 \%$ Pontamine Sky Blue in $0.5 \mathrm{~m}$ sodium acetate. Single-unit activity was amplified, filtered, and discriminated. Undiscriminated output was viewed on a Tektronix storage oscilloscope and discriminated output was digitized for the construction of poststimulus histograms using a Cambridge Electronic Design 1401 computer interface. Recordings were made in parallel tracks $(200-400 \mu \mathrm{m}$ apart) along the mediolateral axis (from 4.8 to 5.5 $\mathrm{mm}$, relative to the mid-sagittal suture) and the anteroposterior axis (from 5.0 to $7.0 \mathrm{~mm}$, relative to the interaural line). Drugs were iontophoresed in the vicinity of the cell being recorded. The center barrel of the five-barrel pipette was filled with $0.9 \%$ saline for automatic current balancing. The remaining barrels were filled with the NMDA antagonist DL-APV [ $50 \mathrm{~mm}$ in $200 \mathrm{~mm} \mathrm{NaCl}(\mathrm{pH}$ 8.0)], or the AMPA antagonist CNQX [ $1 \mathrm{~mm}$ in the $200 \mathrm{~mm} \mathrm{NaCl}$ (pH 9.0)]. All drugs were purchased from Research Biochemicals International (Natick, MA). Agents were iontophoretically ejected with negative currents and retained with positive current. Placements of extracellular recordings were marked by depositing Pontamine Sky Blue ionto-

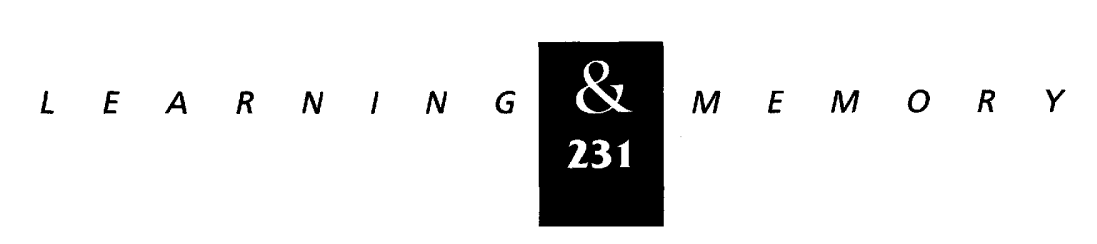


phoretically. Dye deposits were visualized histologically using standard procedures (Li et al. 1995).

For intracellular recording, quartz micropipettes pulled from a Model P-2000 laser puller (Sutter Instruments) were filled with $0.5 \%$ biocytin (Sigma Chemical) in $2 \mathrm{M}$ potassium acetate ( 40 $\mathrm{M} \Omega-100 \mathrm{M} \Omega$ ). Electrode potentials were amplified by a headstage amplifier connected to an Axoclamp-2B Amplifier (Axon instruments). Onand off-line data acquisition and analysis was accomplished using a Digidata 1200 interface (Axon Instruments) between an Axoclamp-2B preamplifier and a personal computer (Gateway 2000) utilizing PClamp 6.0.2 software (Axon Instruments). The intracellular results were limited to data obtained from cells that exhibited a stable resting membrane potential of at least $-55 \mathrm{mV}$ and that had action potentials that were $\geqslant 45 \mathrm{mV}$ in amplitude, as measured from the beginning of the fastrising phase to the spike peak. The noncompetitive NMDA blocker MK-801 (Sigma), was administered i.v. ( $1 \mathrm{mg} / \mathrm{kg}$ ) during intracellular recording. After intracellular recording of the electrophysiological properties of the LA neurons, biocytin was iontophoretically injected into the cell by passing hyperpolarizing current $(0.2-0.3 \mathrm{nA}, 200 \mathrm{msec}$ on, $800 \mathrm{msec}$ off) through the recording electrode (8-70 $\mathrm{min}$ ). Biocytin-injected animals survived 15 min-5 hr and were then perfused with normal saline followed by a fixative containing $4 \%$ paraformaldehyde. The brains were removed and stored in the same fixative solution with $20 \% \mathrm{su}$ crose overnight at $4^{\circ} \mathrm{C}$. Blocks of tissue containing the amygdala were cut into $50 \mu \mathrm{m}$ sagittal sections using a sliding microtome. To visualize the biocytin-filled cells, the sections were processed using the avidin-biotin horseradish peroxidase complex (ABC) in $0.2 \%$ triton PBS for at least $2 \mathrm{hr}$ and then washed several times in PBS and reacted with $3^{\prime} 3^{\prime}$ diaminobenzidine tetrahydrochloride dihydrate (DAB) and hydrogen peroxide. Sections were dehydrated and coverslipped. Detailed reproduction of the filled and recovered neurons was achieved using the Eutectic Neuron Tracing System, allowing for accurate reconstruction of the neuron across consecutive tissue sections.

\section{Results}

\section{EXTRACELLULAR RECORDING OF CONVERGENT RESPONSES}

Single unit activity was recorded extracellularly in the LA in response to electrical stimulation of the auditory thalamus and cortex to determine whether the same cell could be activated from both areas. In the absence of stimulation, these cells were either silent or had very low rates of spontaneous activity, as reported previously (Clugnet et al. 1990; Bordi and LeDoux 1992; Li et al. 1995).

Cells responsive to stimulation of either pathway were numerous, and it was not difficult to find cells responsive to both stimulations. Extracellular spike waveforms were monitored and used to verify that the individual cells responded to both stimulations. For illustrative purposes, characteristics of seven cells that responded to stimulation of both the auditory thalamus and cortex will be described. These were obtained from a sample of 12 cells that were identified by their responsivity to stimulation of one or two pathways. Each of the seven cells showed phasic excitation in response to thalamic and cortical stimulation, with a single spike typically locked to stimulus onset (Clugnet et al. 1990; Bordi and LeDoux 1992; Li et al. 1995). The shortest latency recorded in the thalamo-amygdala pathway was $4 \mathrm{msec}$ and the shortest in the cortico-amygdala pathway was 8 msec. Mean latency of the thalamo-amygdala pathway was $7.7 \pm 0.6 \mathrm{msec}($ mean \pm S.E. $)$ and mean latency of the cortico-amygdala pathway was $11.34 \pm 0.50 \mathrm{msec}$. The anatomical locations of these cells is shown in Figure 2.

DIFFERENTIAL CONTRIBUTION OF NMDA AND AMPA RECEPTORS TO SYNAPTIC TRANSMISSION IN THE THALAMO-AMYGDALA AND CORTICO-AMYGDALA PATHWAYS

Previously, we examined the effects of iontophoretic application of NMDA and AMPA antagonists on synaptic transmission in the thalamoamygdala pathway (Li et al. 1995). Blockade of either NMDA or AMPA receptors interfered with transmission. In the following we first determined whether both NMDA and AMPA receptors are required for cortico-amygdala transmission, and then examined the contribution of these receptors to transmission at cells that receive convergent inputs. The locations of the cells studied was similar to those shown in Figure 2.

A total of 10 neurons responding to stimulation of the auditory cortex were recorded in the LA. Iontophoretic application of CNQX attenuated the spikes evoked by auditory cortex stimulation

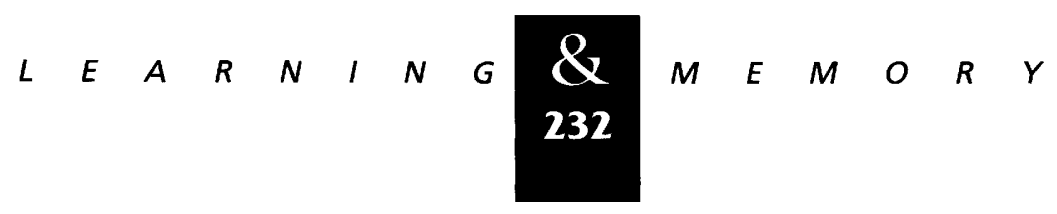




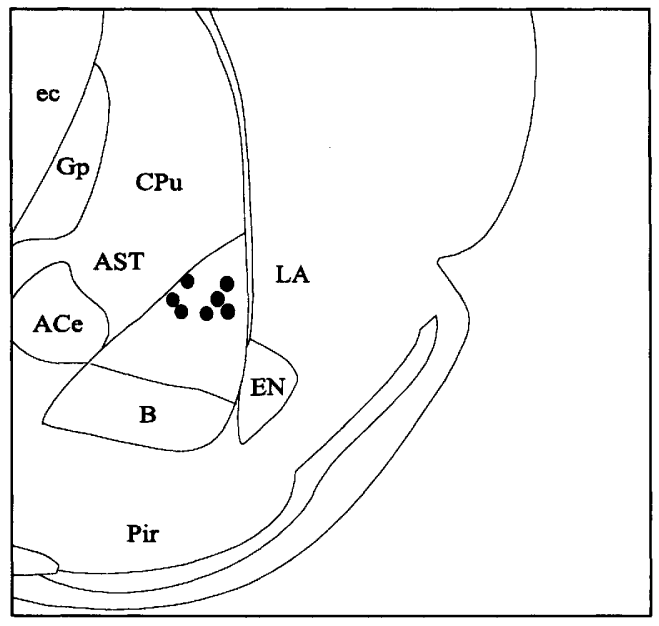

Figure 2: Anatomical location of extracellularly recorded neurons in the LA that received convergent input from both the MGm/PIN and the auditory cortex. Electrode placement was verified histologically by ejecting Pontamine Sky Blue at the recording site.

in all 10 neurons. For the purpose of quantification, the cell was considered to be blocked if the number of the discriminated spikes counted was reduced by at least $50 \%$ relative to the preceding control period (Li et al. 1995). APV attenuated the evoked spikes in only 2 out of 10 neurons. Typical examples of the effects of APV and CNQX on the same cell are shown in Figure 3A. Figure 3B shows the pooled poststimulus time histograms for the 10 cells tested with both APV and CNQX.

For comparison with our previous results $(\mathrm{Li}$ et al. 1995), we also examined the effects of iontophoretic application of CNQX and APV on unit responses of eight cells elicited by stimulation of the MGB. The excitatory response was blocked by CNQX in five of the eight cells and by APV in all eight. Typical poststimulus histograms showing the effects of APV and CNQX on an individual cell are shown in Figure 4A. Figure 4B shows the pooled poststimulus time histograms for the eight cells tested with both APV and CNQX.

We also examined the effects of APV and CNQX on convergent transmission in the two pathways. Of the seven neurons that responded to stimulation from both inputs, iontophoretically applied CNQX blocked evoked spikes from the auditory cortex in all seven neurons, whereas APV only blocked spikes in one neuron. In contrast, for the responses elicited by MGB stimulation, CNQX blocked the spikes in five of the seven cells and APV in six of the seven. Typical poststimulus histograms of the effects of APV and CNQX on a single cell activated by both auditory cortex and MGB stimulation are shown in Figure 5.

In summary, iontophoresis of CNQX blocked transmission in both the thalamic and cortical
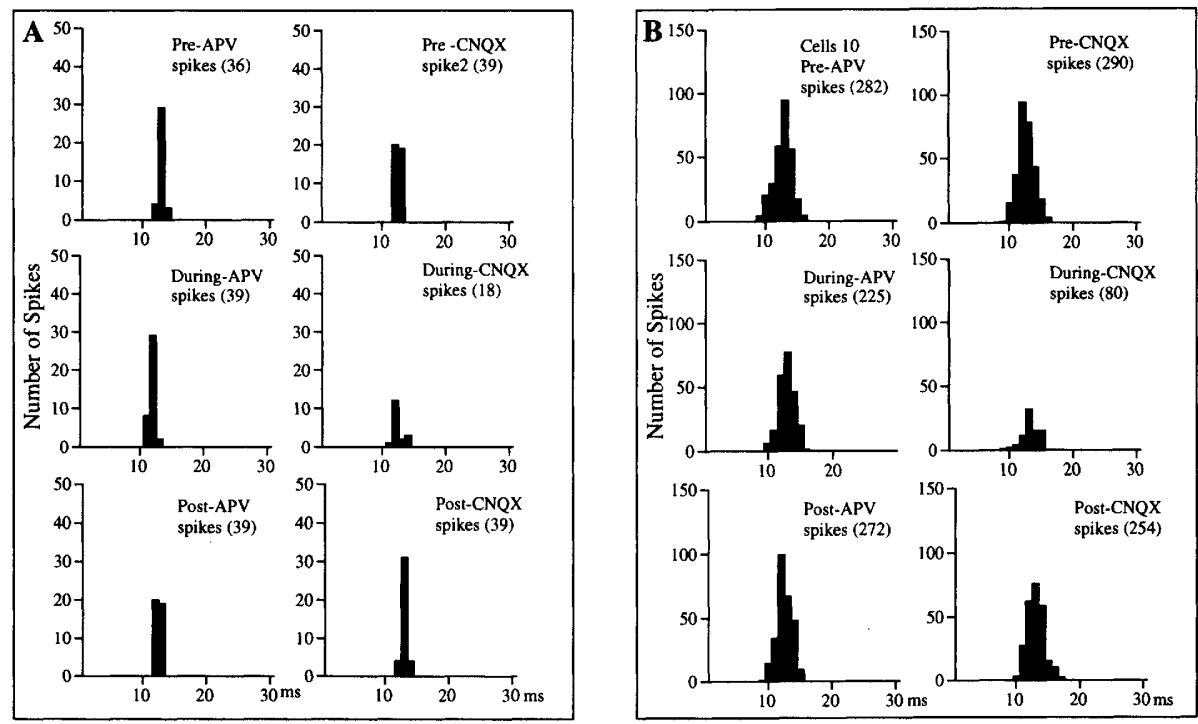

Figure 3: Poststimulus time histograms from extracellular recordings demonstrating the differential effects of iontophoretically applied APV and CNQX on auditory cortex evoked spike activity in the LA. (A) Representative response from a single neuron before, during, and after drug application. Spike activity was reduced more than $50 \%$ during the CNQX treatment. APV had little or no effect. (B) Pooled histograms from 10 LA neurons demonstrating evoked activity from auditory cortex stimulation. During CNQX but not APV application, spike activity was dramatically reduced.

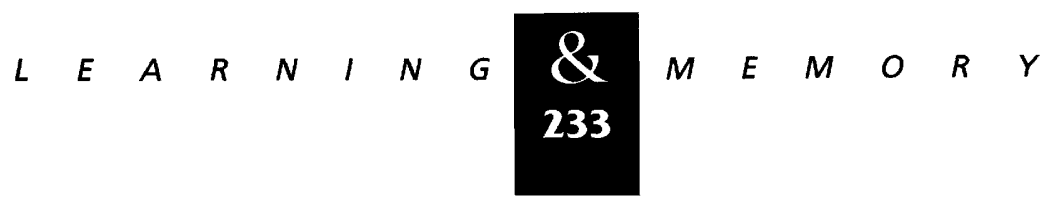


Li et al.
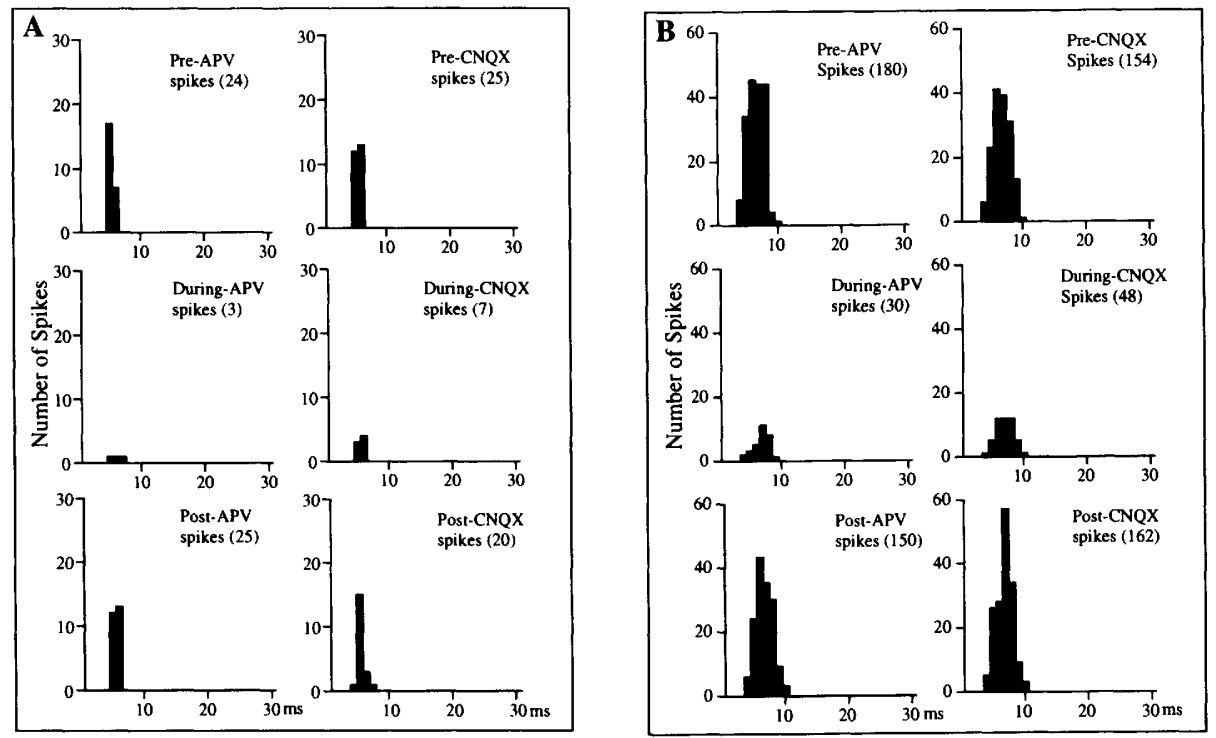

Figure 4: Poststimulus time histograms from extracellular recordings demonstrating the effects of iontophoretically applied APV and CNQX on MGB-evoked spike activity in the LA. (A) A typical histogram showing evoked activity from a single LA neuron before, during, and after drug application. Spikes were significantly reduced during both the APV and CNQX application, and normal activity resumes postdrug. $(B)$ Pooled histograms from eight neurons. The excitatory response was blocked by APV in all eight neurons, and CNQX blocked activity in five of the eight neurons.

pathways to LA, but iontophoresis of APV only blocked thalamic transmission. Thus, the thalamoamygdala pathway uses both NMDA and AMPA receptors in routine transmission, whereas the cortico-amygdala pathway uses only AMPA receptors.

\section{INTRACELLULAR RECORDINGS ALSO SHOW CONVERGENT SYNAPTIC INPUTS}

To obtain further evidence that individual the LA cells receive convergent monosynaptic inputs from the auditory thalamus and cortex and use different receptor mechanisms, intracellular recordings were made in $13 \mathrm{LA}$ cells (average resting membrane potential $71.34 \pm 1.84 \mathrm{mV}$ ) that responded to stimulation of either one or both pathways. A cell was considered to receive a monosynaptic input from one of the afferent structures if it responded to stimulations with relatively short onset EPSP latencies and had consistent onset EPSP latencies (over a range of stimulus intensities) and a low degree of spike latency variability (varied less than $1.5 \mathrm{msec}$ ) from trial to trial (Sugimori et al. 1978). A cell was considered to receive convergent synaptic inputs if it was monosynaptically activated from both areas. All 13 LA cells were morphologically identified by intracellular injection of biocytin. Recording sites are shown in Figure 6A. A reconstructed representative LA cell, as seen after intracellular staining with biocytin, is shown in Figure 6B.

Stimulation of the auditory thalamus induced postsynaptic potentials in all 13 of the neurons tested (Figure 7A). In 12 of these, the evoked excitatory potentials were followed by IPSPs. The average onset latency of the EPSP was $3.12 \pm 0.28$ msec in response to thalamic stimulation, with an average amplitude of $11.56 \pm 1.41 \mathrm{mV}$. Action potentials occurred in seven of the cells with EPSPs. The latency (measured from the beginning of the fast-rising phase of the spike) of the intracellularly recorded action potential, $5.79 \pm 1.09 \mathrm{msec}$, is consistent with extracellular responses reported above and described previously (Clugnet et al. 1990; Li et al., 1995).

Stimulation of the auditory cortex also evoked potentials in 12 of the 13 cells. In 11 of these, an EPSP/IPSP sequence occurred. The EPSP onset latencies averaged $5.94 \pm 0.80 \mathrm{msec}$ and had an average amplitude of $11.58 \pm 1.6 \mathrm{mV}$. The remaining cell responded only with an evoked IPSP. Evoked spikes were seen in 7 of the 12 cells with EPSPs (Figure 7B). As with thalamic stimulation, typically a single spike occurred. The action potential latencies averaged $12.67 \pm 2.45 \mathrm{msec}$, consistent

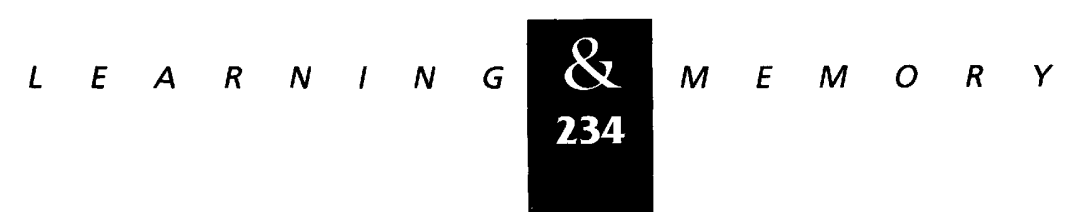


Cortico-amygdala pathway

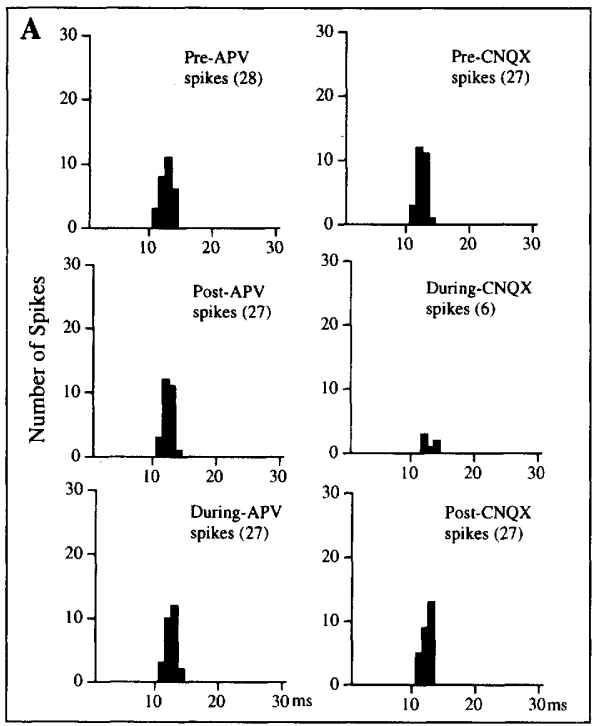

Thalamo-amygdala pathway

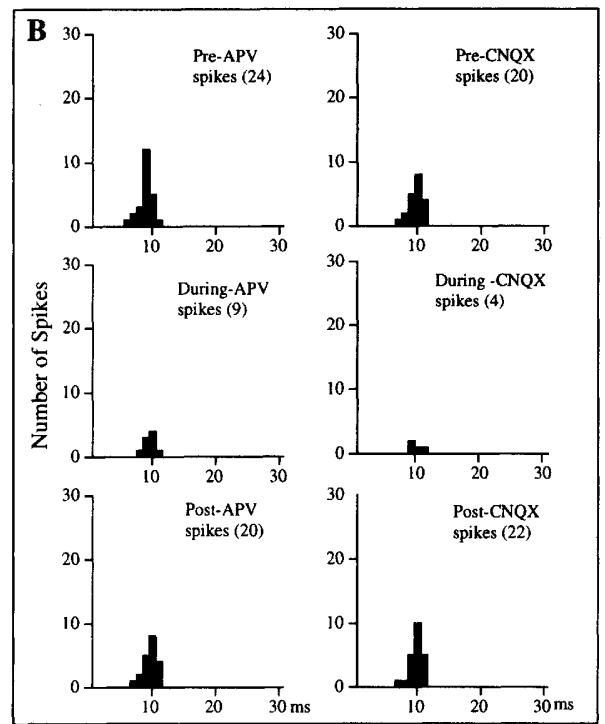

Figure 5: Extracellular recording demonstrating convergent input onto a single LA neuron from both the corticoamygdala pathway and the thalamo-amygdala pathway, and the effects of APV and CNQX on evoked activity. (A) Representative poststimulus histograms demonstrating the effects of APV and CNQX on a single LA neuron. CNQX significantly reduced evoked spike activity from auditory cortex stimulation. In contrast, APV had little or no effect. (B) Representative poststimulus histograms from the same LA neuron showing evoked spike activity generated from MGB stimulation. Both APV and CNQX attenuated the evoked spikes.

with the extracellular recording results (see above).

Evidence was obtained for convergent synaptic input onto a single cell in 12 of the 13 neurons. These cells responded with EPSPs or action potentials to stimulation of both pathways. These potentials were recorded from approximately the same resting membrane potential within each cell. However, because of the inherent fluctuations in membrane potentials observed in in vivo recordings, it is not possible to exactly control the resting membrane potential within each cell over time. In 12 of the 13 cells the EPSP elicited by stimulation of each pathway had a constant onset latency with increasing stimulus intensities suggesting monosynaptic activation (see above). In the one cell that responded to cortical stimulation with an IPSP, the onset latency was long $(>20$ msec) and varied considerably from trial to trial, suggesting that a polysynaptic pathway was involved in this response. Figure 8 illustrates convergence of afferents activity onto a single LA neuron. This cell is anatomically reconstructed in Figure $6 \mathrm{~B}$.
INTRACELLULAR EVIDENCE FOR NMDA RECEPTOR INVOLVEMENT IN THALAMO-AMYGDALA BUT NOT CORTICO-AMYGDALA SYNAPTIC TRANSMISSION

The combination of intracellular recording and iontophoresis in vivo would be ideal for examining the contribution of different receptors to synaptic transmission. Though possible (Durand 1993), this is technically difficult. As a result, we used a more practical approach. Our main concern was to show the differential involvement of NMDA receptors in the two pathways; therefore, we administered systemically the noncompetitive NMDA antagonist MK-801 which crosses the blood-brain barrier and is known to block central NMDA receptors under such conditions (Croll et al. 1992; Durand 1993; Coan et al. 1987).

A total of eight neurons were recorded intracellularly in the LA (or in immediately adjacent portions of the basal nucleus) and the evoked action potentials from MGm and/or TE3 stimulation were analyzed. For the control condition, stable intracellular recordings were obtained and evoked responses from the MGm/PIN and/or TE3 were

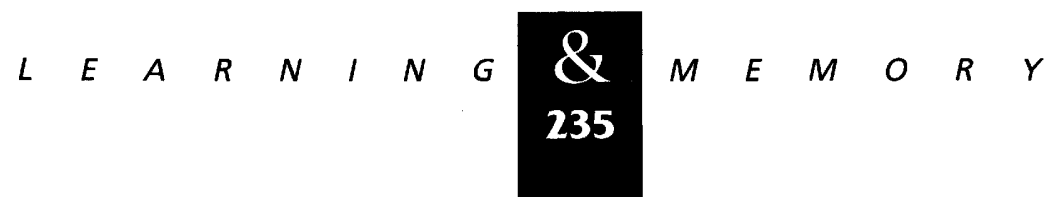


A
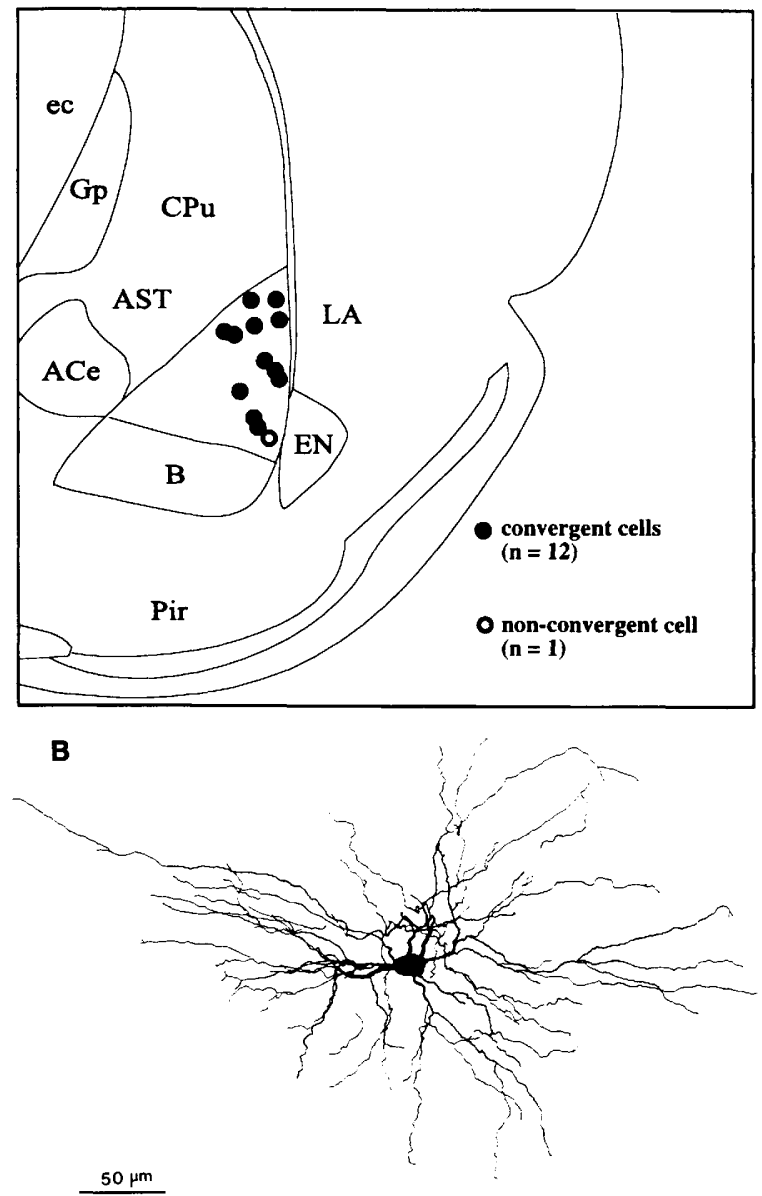

Figure 6: $(A)$ In vivo intracellular recording sites from 13 cells tested in the LA. For 12 of 13 LA neurons, convergence was present, as demonstrated by a relatively short latency postsynaptic potential, consistent postsynaptic potential or action potential onset latency, and independent activation from each auditory region. (B) A representative $L A$ neuron, reconstructed after intracellular injection with $0.5 \%$ biocytin and visualized with an $A B C / D A B$ reaction. Seven sections, each $50 \mu \mathrm{m}$ thick, were required for reconstruction of the dendritic field in the rostrocaudal direction. Bar, $50 \mu \mathrm{m}$.

recorded. Then, MK-801 was administered and the stimulation and recording of responses was repeated in the same neuron.

There was no significant difference in the resting membrane potentials before, during, and after drug infusion $\left(F_{2,7}=0.5, P=0.622\right)$. The average resting membrane potentials of the neurons in the three conditions were $72.2 \pm 2.4 \mathrm{mV}, 73.9 \pm 2.1$ $\mathrm{mV}$, and $71.9 \pm 2.9 \mathrm{mV}$, respectively. In addition, average EPSP amplitudes occurring in the MGm stimulated pathway were $14.4 \pm 1.1 \mathrm{mV}, 17.9 \pm 1.9$
$\mathrm{mV}$, and $15.6 \pm 2.3 \mathrm{mV}$ before, during, and after drug infusion periods, respectively. These were not significantly different as well $\left(F_{2,5}=1.00\right.$, $P=0.39$ ). In the TE3 stimulated pathway, the averaged EPSP amplitudes were $14.2 \pm 2.2 \mathrm{mV}$, $18.3 \pm 4.4 \mathrm{mV}$, and $14.5 \pm 3.7 \mathrm{mV}$ during these same drug conditions, and these were not significantly different $\left(\mathrm{F}_{2,3}=1.00, P=0.41\right)$.

Of the eight neurons recorded, five were from rats with stimulating electrodes placed in both the TE3 and MGm, two had stimulating electrodes placed in MGm only, one had the stimulating electrode placed in TE3 only. Of the neurons recorded from rats with both stimulating electrodes, four out of five had action potentials evoked from stimulation of both pathways (convergence); the remaining neuron had evoked action potentials from stimulation of the MGm/PIN only. Both neurons recorded from the rat with only the MGm stimulating electrode demonstrated evoked action potentials, and the rat with only the TE3 stimulating electrode also demonstrated evoked action potentials.

For three of the four neurons that responded to both pathways, the number of $\mathrm{MGm} / \mathrm{PIN}$ evoked spikes was dramatically reduced or completely blocked following MK-801 injection. There was no effect of MK-801 on any of the TE3 evoked spikes. Of the three cells that had evoked spikes from MGm/PIN but not TE3, MK-801 completely blocked spikes in all three cases. MK-801 had no effect on the spikes evoked from the one cell activated by TE3 but not MGm/PIN stimulation. Figure 9 demonstrates the differential effects of MK801 on evoked activity in an LA neuron that receives convergent afferents from the $\mathrm{MGm} / \mathrm{PIN}$ and TE3. Thus, across the several experiments involving cells responding to stimulation of either or both MGm/PIN and TE3, MK-801 blocked or reduced the number of spikes evoked by $\mathrm{MGm} / \mathrm{PIN}$ stimulation in six of seven cells and had no effect on the spikes elicited from TE3 stimulation in five of five cells. Though somewhat preliminary, given the relatively small sample of cells studied, these findings corroborate our extracellular results in suggesting that NMDA receptors are involved in thalamo-amygdala but not cortico-amygdala transmission.

\section{Discussion}

In the present study we examined whether individual cells in the LA receive inputs from both the auditory thalamus and auditory cortex and

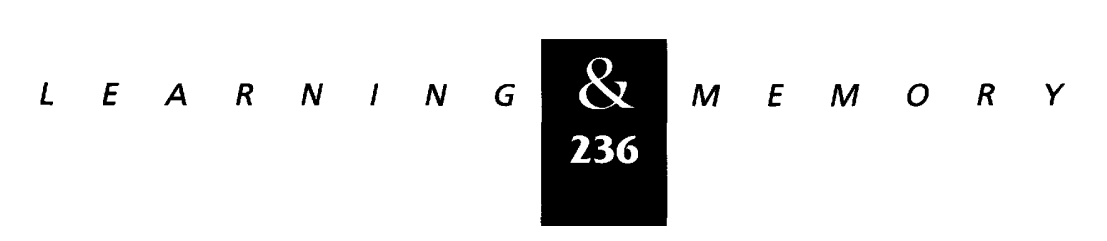


A

MGm/PIN stimulation
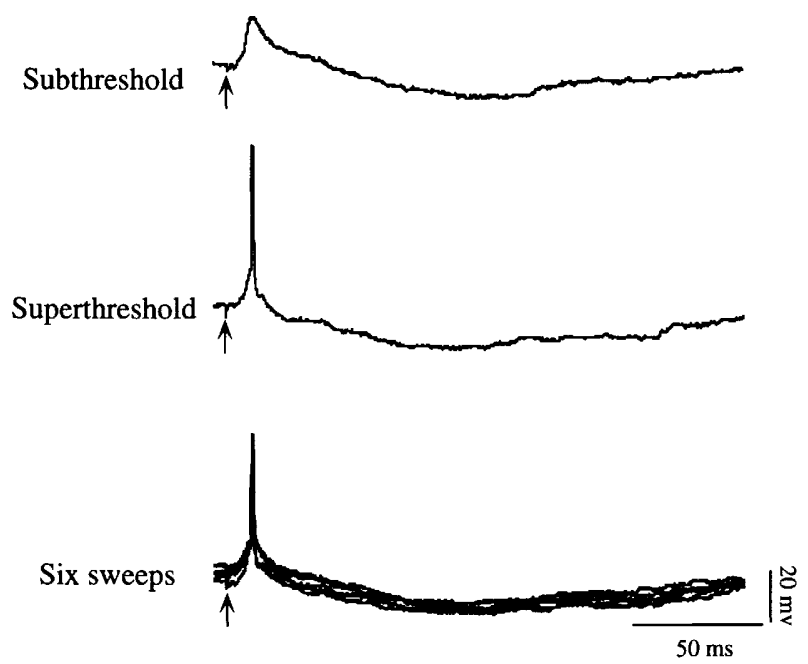

B

Auditory cortex stimulation
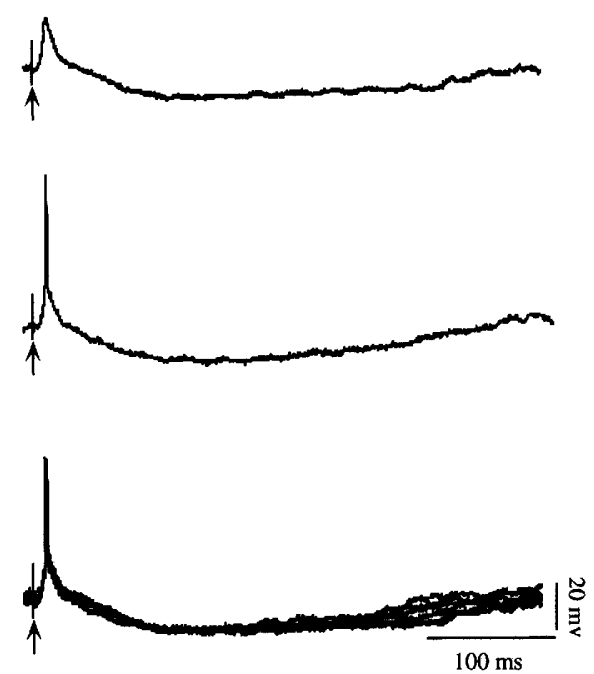

Figure 7: In vivo intracellular recording in two LA neurons demonstrating EPSPs and action potentials evoked from stimulation of the MGB or auditory cortex. (A) Representative intracellular recording from a single LA neuron demonstrating evoked potentials from MGB stimulation. $(B)$ Representative intracellular recording shows that evoked potentials resulted from stimulation of the auditory cortex.

whether the same or different postsynaptic receptor mechanisms mediate synaptic transmission over the two pathways. Our results show that individual cells do indeed receive convergent inputs and that different excitatory amino acid receptor mechanisms are involved.

\section{CONVERGENT INPUTS TO THE LA FROM THE AUDITORY THALAMUS AND CORTEX}

Anatomical tracing studies have shown that projections originating in the auditory thalamus

A

MGm/PIN stimulation

Subthreshold
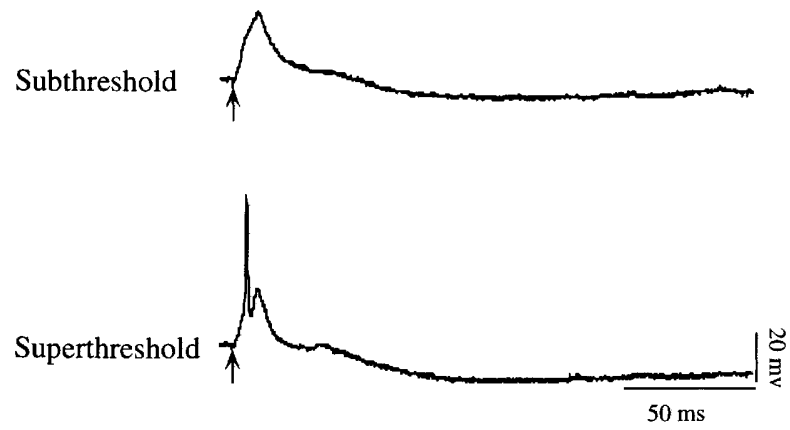

and auditory cortex terminate in overlapping regions of the amygdala, and especially in the LA (LeDoux et al. 1990b, 1991a; Romanski and LeDoux 1993b). In the present study we used extracellular and intracellular recording techniques to demonstrate that the projections converge onto single neurons. In physiological studies of this type, the existence of convergence is dependent upon the demonstration that the same cell is activated by stimulation of the two sites and that the activations are monosynaptic (Sugimori et al. 1978; Mello et al. 1992; O'Donnell and Grace

B

Auditory cortex stimulation
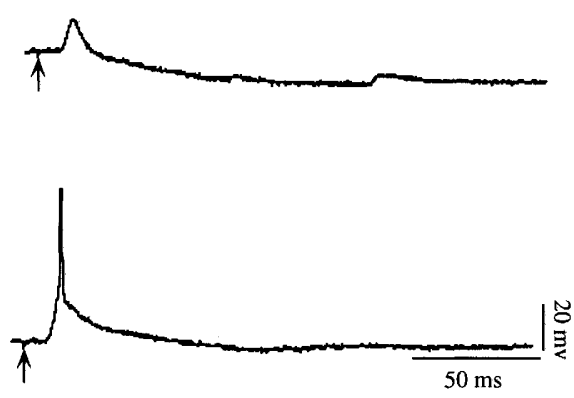

Figure 8: Representative intracellular recording from a single LA neuron demonstrating the convergence of afferent inputs from the MGm/PIN and auditory cortex. Both subthreshold EPSPs and action potentials are shown for individual sweeps.

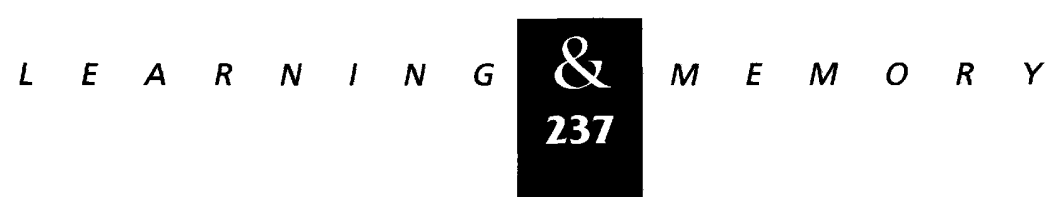


Li et al.

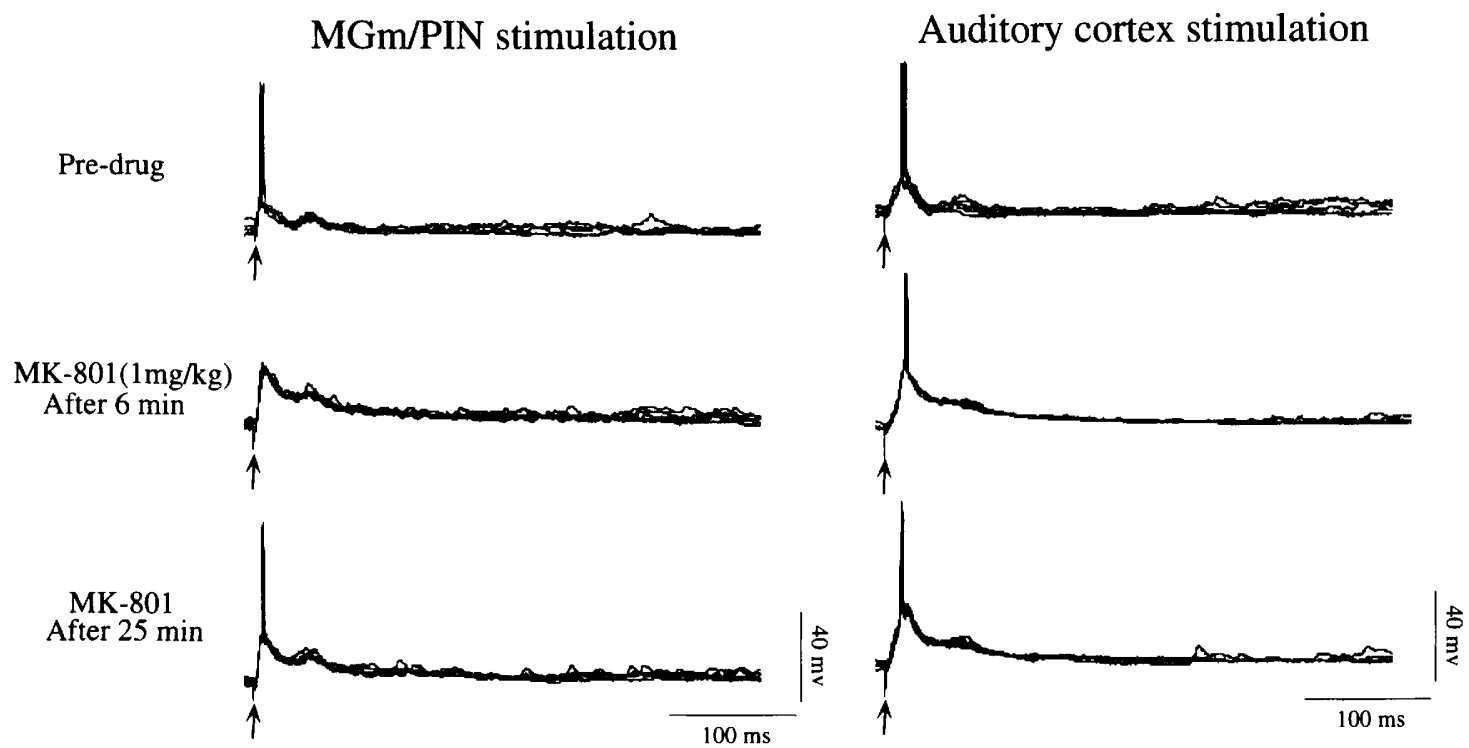

Figure 9: Effects of NMDA blockade on the action potentials elicited from a single cell by stimulation of the MGm/PIN and TE3. Stimulation of each area separately elicited an intracellularly recorded action potential at average latency of 6.58 msec from the MGm/PIN and $14.15 \mathrm{msec}$ from the TE3. After i.v. injection of MK-801 (1 mg/kg), the MGm/PIN-evoked action potential was completely blocked. This effect was reversed after $25 \mathrm{~min}$. There was no drug effect on action potentials evoked from auditory cortex.

1995). By carefully analyzing the waveforms of the cells activated by the two stimulation sites, we were able to determine with some confidence that the same cell was being activated in the extracellular recordings. The delay and consistency of the latency from trial to trial suggested monosynaptic activation. In the intracellular studies, any uncertainty about whether the same cell was activated is further eliminated because the electrode can only rest inside one cell. Monosynaptic activations can also be determined with more certainty in intracellular studies because the existence of a shortlatency EPSP with a consistent onset latency (with increasing stimulus intensity) adds a dimension that is lacking in extracellular recordings (Sugimori et al. 1978). Our results strongly suggest that single LA neurons were activated monosynaptically by stimulation of the two pathways.

\section{RECEPTOR MECHANISMS INVOKED IN} THALAMO-AMYGDALA AND CORTICO-AMYGDALA SYNAPTIC TRANSMISSION

Previously, we found that routine synaptic transmission in the thalamo-amygdala pathway is mediated by the combined involvement of the two major classes of excitatory amino acid receptors, AMPA and NMDA receptors (Li et al. 1995). Thus, extracellular unit responses evoked in the LA by stimulation of the MGB could be blocked by iontophoresis of antagonists of either AMPA or NMDA receptors. This contrasts with the classic picture of excitatory transmission derived from studies of synapses in the hippocampus, especially the CA1 region, where NMDA receptors are not necessary for routine synaptic transmission and only become involved in certain circumstances, particularly circumstances that lead to synaptic plasticity, such as high-frequency stimulation of afferents (Brown et al. 1988; Bliss and Collingridge 1993; Malenka and Nicoll 1993). The involvement of NMDA receptors is not an artifact of electrical stimulation of the afferent pathways, as NMDA blockade also affected spikes elicited by peripheral auditory stimuli ( Li et al. 1995). In the present study, using extracellular recordings and microiontophoresis, we confirmed the involvement of NMDA receptors in thalamo-amygdala transmission. In addition, we found that cortico-amygdala pathways utilize AMPA but not NMDA receptors in routine transmission.

We also wanted to pursue the issue of differential receptor involvement in the two pathways using intracellular recordings. It is possible (Durand 1993), but difficult, to combine microiontophoresis or microinjections with intracellular re-

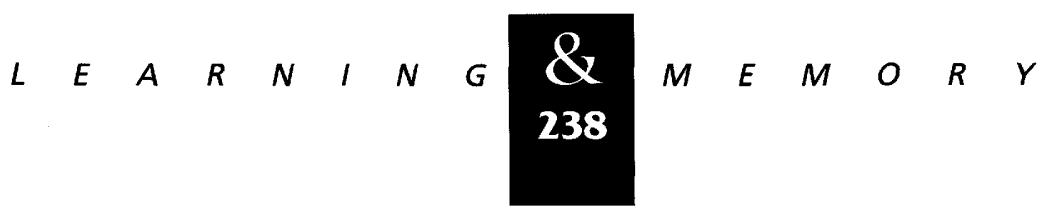


cordings in vivo. An alternative approach involves the use of the noncompetitive NMDA antagonist MK-801, which can be given systemically because it crosses the blood-brain barrier (Croll et al. 1992; Durand 1993). Systemic MK-801 eliminated action potentials elicited by stimulation of the MGB but not by stimulation of the auditory cortex, thus confirming the general pattern of results obtained in the extracellular recordings. Given that we were studying monosynaptic activations, we are fairly confident of the site of action of systemic MK-801 in spite of the fact that many other synapses were affected.

The intracellular physiology analyzed in these cells is consistent with previous studies using in vivo intracellular recording techniques in the LA (Mello et al. 1992; Paré et al. 1995). For example, the neurons had little or no spontaneous activity and resting membrane potentials were -65 to $-85 \mathrm{mV}$. When there was spontaneous activity, it took the form of either random individual spikes or brief bursts of several spikes. Examination of the action potential waveform demonstrated a short after-depolarization prior to the after-hyperpolarization. These in vivo findings regarding basic physiological properties of the LA neurons are also consistent with results from in vitro studies (Chapman et al. 1990; Gean and Chang 1991, 1992; Rainnie et al. 1991a,b, 1993; Washburn and Moises 1992; Sugita et al. 1993).

The time course for NMDA receptor activation is known to be longer than the fast-acting non-NMDA component (Thomson 1986; Gean and Shinnick-Gallagher 1988a,b; Thomson et al. 1989; Gean 1990; Hessler et al. 1993; Xiang et al. 1994). Thus, non-NMDA-mediated effects are seen in the earlier phase of the EPSP, whereas the NMDA-mediated components are associated with the later phase. In the thalamo-amygdala pathway, which uses NMDA receptors in routine transmission, blockade of NMDA receptors did not consistently reduce late component EPSPs. The lack of a clear effect on the late EPSP most likely does not reflect unique properties on NMDA receptors in the LA. Instead, the results may be related to other factors. For example, with systemic injections it is not possible to control the concentration of the drug reaching the cells being studied. As a result, there may have been an incomplete blockade of the NMDA receptor coupled cation channel, such that at the given dose, spike activity was inhibited but not EPSP related events. We used $1 \mathrm{mg} / \mathrm{kg}$ i.v., but other studies have used as much as $3 \mathrm{mg} / \mathrm{kg}$ (Du- rand 1993). Perhaps a higher dose would block the NMDA component of the EPSP more effectively. Alternatively, subtle changes may be occurring that are not readily discernible. In addition, systemic administration results in global widespread effects on numerous cell types throughout the brain. As a result, it is not possible to determine whether the compound, in addition to direct action on the LA neurons, might also affect other brain regions and alter the LA neuronal activity indirectly.

TEMPORAL PROPERTIES OF TRANSMISSION IN THE THALAMO AMYGDALA AND CORTICO AMYGDALA PATHWAYS: IMPLICATIONS FOR STIMULUS PROCESSING AND PLASTICITY

The results of our study are perhaps best understood in light of the temporal characteristics of acoustic response latencies in the auditory thalamus, auditory cortex, and LA. Following the onset of an auditory stimulus, the earliest response latencies in the various nuclei of the rat MGB are $\sim 7-9$ msec (Bordi and LeDoux 1994a) and $\sim 10-$ $12 \mathrm{msec}$ in both the auditory cortex and the LA (Bordi and LeDoux 1992; Quirk et al. 1995; G.J. Quirk, J.L. Armony, and J.E. LeDoux, pers. comm). Electrical stimulation of the MGB elicits responses in the LA (Clugnet et al 1990; Li et al 1995) and auditory cortex (Quirk et al. 1996) with latencies of about $4-5 \mathrm{msec}$. Stimulation of the auditory cortex typically elicits responses in the LA with latencies of $\sim 10-12 \mathrm{msec}$. Thus, the IA and auditory cortex receive auditory inputs at about the same time ( $\sim 10-12 \mathrm{msec}$ after auditory stimulus onset). The earliest possible auditory response in the LA by way of the auditory cortex is thus $\sim 20$ msec after stimulus onset. Auditory responses in the LA with latencies less than $20 \mathrm{msec}$ are thus totally dependent upon thalamic transmission, whereas responses with latencies greater than 20 msec could be accounted for by transmission over either or both pathways.

The kinetics of NMDA receptors are such that once activated the channels remain open considerably longer (tens to hundreds of milliseconds), whereas AMPA receptor channels are open only briefly (a few milliseconds) (Hessler et al. 1993; Xiang et al. 1994). The involvement of NMDA receptors in thalamic transmission may provide a mechanism through which LA cells maintain responsivity to thalamic input while the cortex cre-

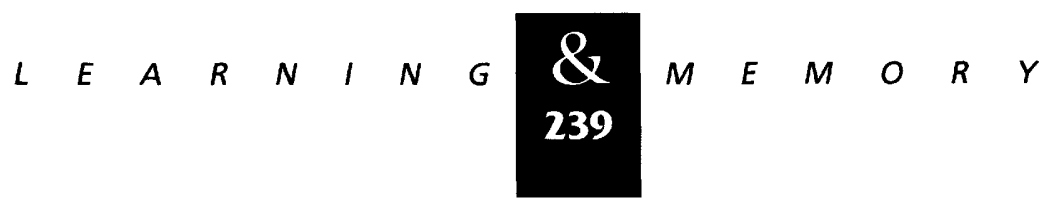


Li et al.

Figure 10: Lateral amygdala integration of inputs from auditory thalamus and auditory cortex. The earliest auditory inputs reach the auditory thalamus $\sim 8 \mathrm{msec}$ after stimulus onset. These inputs are then transmitted to the auditory cortex and to the LA, which both respond at about the same time (beginning $\sim 12 \mathrm{msec}$ after stimulus onset). Given these latencies, the earliest responses in the LA can only be attributable to the thalamic input as at least an additional $8 \mathrm{msec}$ is required for auditory signals from the cortex to reach the LA. The involvement of NMDA receptors and their slow kinetics, in synaptic transmission from the auditory thalamus, may provide a means by which LA cells can remain active in response to thalamic stimulation. In the illustration, an auditory thalamic input is depicted as activating a large subset of LA neurons (O) and the cortical input a much smaller subset $(\odot)$. In this way, cortical inputs that arrive at cells that are active (depolarized by the prolonged NMDA currents

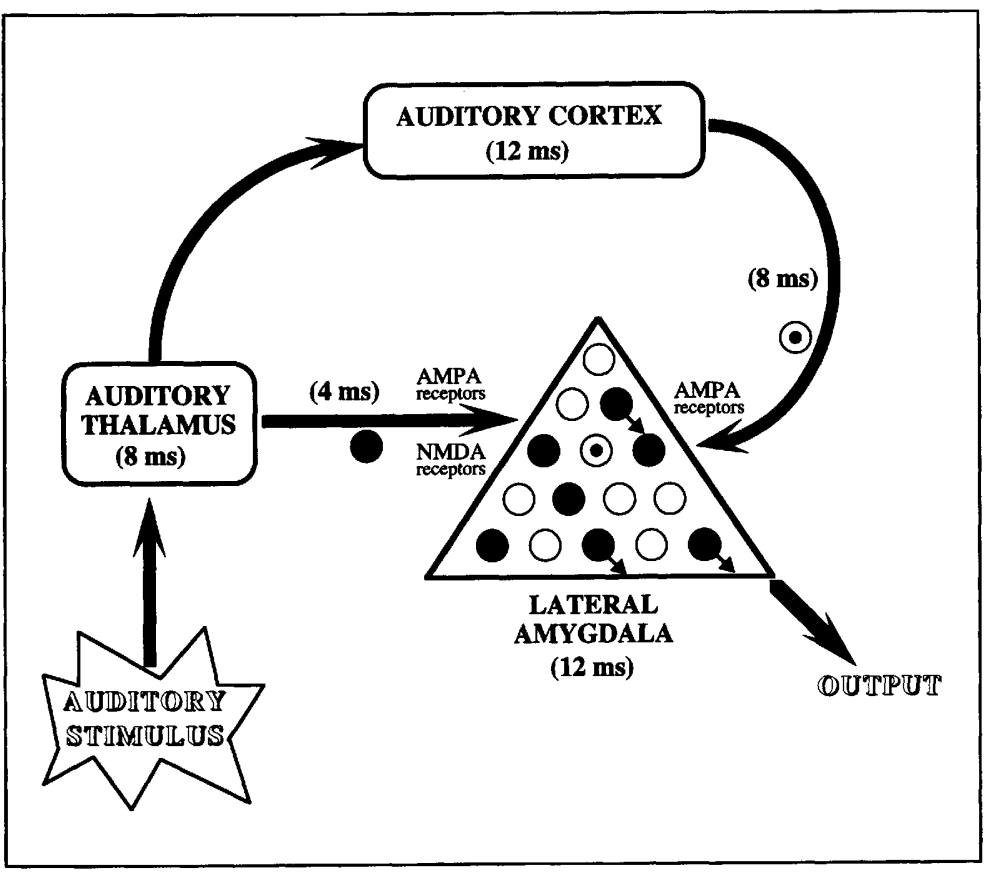
produced by thalamo-amygdala activation) are more likely to fire in response to cortical inputs ( 0 ). This saves neuronal processing time, which may facilitate rapid behavioral responses to dangerous stimuli.

ates its enriched stimulus representations. In this way, the early arriving signals from the thalamus could select from the total population of LA cells those that are most relevant, given the crude stimulus analysis performed at the thalamic level. These cells are thus activated, either at supra- or sub- threshold levels, by the combined action of NMDA and AMPA receptors, and they remain active, because of the slow kinetics of the NMDA receptor, sufficiently long enough for the signals to arrive from the auditory cortex. The cortical signals further select from the population of LA neurons those that are most relevant to the cortically processed representation of the stimulus. LA cells that are under the influence of the prolonged NMDA response from thalamic transmission are more easily driven toward the firing threshold (Fig. 10). Much remains unknown about how plasticity occurs in the LA when auditory and noxious somatosensory inputs are integrated. However, the elucidation of mechanisms underlying the processing of auditory signals over these parallel pathways is an important first step.

Because thalamic and cortical inputs to the LA exhibit experience dependent plasticity (Chapman et al. 1990; Clugnet and LeDoux 1990; Rogan and LeDoux 1995), and both cellular changes occur in both pathways during emotional learning
(Quirk et al. 1995), the present findings implicating different receptor processes in transmission in the two pathways suggest that somewhat different mechanisms may also underlie the plasticity occurring in each. A challenge for the future is to identify the molecular mechanisms underlying plasticity in each pathway, and to determine how these mechanisms interact to give rise to learning at the level of behavior.

\section{Acknowledgments}

The work reported here was supported by U.S. Public Health Service Grants R01 MH 46516, R37 MH 3774, and $\mathrm{K} 02 \mathrm{MH} 00956$. The authors thank Jorge Armony for comments on the manuscript.

The publication costs of this article were defrayed in part by payment of page charges. This article must therefore be hereby marked "advertisement" in accordance with 18 USC section 1734 solely to indicate this fact.

\section{References}

Amaral, D.G., J.L. Price, A. Pitkanen, and S.T. Carmichael. 1992. Anatomical organization of the primate amygdaloid complex. In The amygdala: Neurobiological aspects of emotion, memory, and mental dysfunction (ed. J.P. Aggleton), pp. 1-66. Wiley-Liss, New York, NY.

Bliss, T.V.P. and G.L. Collingridge. 1993. A synaptic model

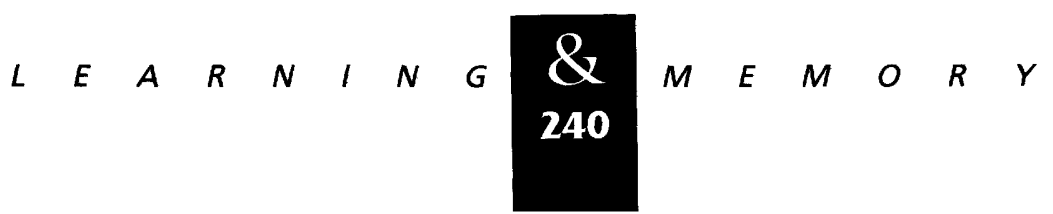


of memory: Long-term potentiation in the hippocampus. Nature 361: 31-39.

Bordi, F. and J.E. LeDoux. 1992. Sensory tuning beyond the sensory system: An initial analysis of auditory properties of neurons in the lateral amygdaloid nucleus and overlying areas of the striatum. I. Neurosci. 12: 2493-2503.

1994a. Response properties of single units in areas of rat auditory thalamus that project to the amygdala. I: Acoustic discharge patterns and frequency receptive fields. Exp. Brain Res. 98: 261-274.

1994b. Response properties of single units in areas of rat auditory thalamus that project to the amygdala. II: Cells receiving convergent auditory and somatosensory inputs and cells antidromically activated by amygdala stimulation. Exp. Brain Res. 98: 275-286.

Bordi, F., J.E. LeDoux, M.C. Clugnet, and C. Pavlides. 1993 Single unit activity in the lateral nucleus of the amygdala and overlying areas of the striatum in freely-behaving rats: Rates, discharge patterns, and responses to acoustic stimuli. Behav. Neurosci. 107: 757-769.

Brown, T.H., P.F. Chapman, E.W. Kairiss, and C.L. Keenan. 1988. Long-term synaptic potentiation. Science 242: 724-728.

Campeau, S. and M. Davis. 1995. Involvement of the central nucleus and basolateral complex of the amygdala in fear conditioning measured with fear-potentiated startle in rats trained concurrently with auditory and visual conditioned stimuli. J. Neurosci. 15: 2301-2311.

Chapman, P.F., E.W. Kairiss, C.L. Keenan, and T.H. Brown. 1990. Long-term synaptic potentiation in the amygdala. Synapse 6: 271-278.

Clugnet, M.C., J.E. LeDoux, and S.F. Morrison. 1990. Unit responses evoked in the amygdala and striatum by electrical stimulation of the medial geniculate body. I. Neurosci. 10: $1055-1061$.

Coan, E.J., W. Saywood, and G.L. Collingridge. 1987. MK-801 blocks NMDA receptor-mediated synaptic transmission and long term potentiation in rat hippocampal slices. Neurosci. Lett. 80: 111-114.

Collingridge, G.L. and T.V. Bliss. 1995. Memories of NMDA receptors and LTP. Trends Neurosci. 18: 54-56.

Croll, S.D., P.E. Sharp, and E. Bostock. 1992. Evidence for NMDA receptor involvement in environmentally induced dentate gyrus plasticity. Hippocampus 2: 23-28.

Davis, M., J.M. Hitchcock, M.B. Bowers, C.W. Berridge, K.R. Melia, and R.H. Roth. 1994. Stress-induced activation of prefrontal cortex dopamine turnover: Blockade by lesions of the amygdala. Brain Res. 664: 207-210.

Durand, J. 1993. Synaptic excitation triggers oscillations during NMDA receptor activation in rat abducens motoneurons. The shell region of the nucleus ovoidalis: A subdivision of the avian auditory thalamus. Eur. J. Neurosci. 5: 1389-1397.

Fanselow, M.S. and J.). Kim. 1994. Acquisition of contextual Pavlovian fear conditioning is blocked by application of an NMDA receptor antagonist $\mathrm{D}, \mathrm{L}$-2-amino-5-phosphonovaleric acid to the basolateral amygdala. Behav. Neurosci. 108: $210-212$.

Gean, P.W. 1990. NMDA receptor-independent epileptiform activity induced by magnesium-free solution in rat amygdala neurons is blocked by CNQX. Neurosci. Lett. 119: 53-55.

Gean, P.W. and F.C. Chang. 1991. Bursting discharges in disinhibited amygdala slices: The role of excitatory amino acid receptors. Neuropharmacology 30: 797-802.

1992. Pharmacological characterization of excitatory synaptic potentials in rat basolateral amygdaloid neurons. Synapse 11: 1-9.

Gean, P.W. and P. Shinnick-Gallagher. 1988a. Characterization of the epileptiform activity induced by magnesium-free solution in rat amygdala slices: An intracellular study. Exp. Neurol. 101: 248-255.

1988b. Epileptiform activity induced by magnesium-free solution in slices of rat amygdala: Antagonism by $\mathrm{N}$-methyl-D-aspartate receptor antagonists. Neuropharmacology 27: 557-562.

Hessler, N.A., A.M. Shirke, and R. Malinow. 1993. The probability of transmitter release at a mammalian central synapse. Nature 366: 569-572.

LeDoux, J.E. 1986. Neurobiology of emotion. In Mind and brain (ed. J.E. LeDoux and W. Hirst), pp. 301-354. Cambridge University Press, New York, NY.

1995. Emotion: Clues from the brain. Annu. Rev. Psychol. 46: 209-235.

LeDoux, J.E. and C.R. Farb. 1991. Neurons of the acoustic thalmus that project to the amygdala contain glutamate. Neurosci. Lett. 134: 145-149.

LeDoux, J.E., P. Cicchetti, A. Xagoraris, and L.M. Romanski. 1990a. The lateral amygdaloid nucleus: Sensory interface of the amygdala in fear conditioning. I. Neurosci. 10: 1062-1069.

LeDoux, J.E., C.F. Farb, and D.A. Ruggiero. 1990b. Topographic organization of neurons in the acoustic thalamus that project to the amygdala. I. Neurosci. 10: 1043-1054.

LeDoux, J.E., C. Farb, and L. Romanski. 1991a. Overlapping projections to the amygdala and striatum from auditory processing areas of the thalamus and cortex. Neurosci. Lett. 134: 139-144.

LeDoux, J.E., C.R. Farb, and T.A. Milner. 1991b. 


\section{Li et al.}

Ultrastructure and synaptic associations of auditory thalamo-amygdala projections in the rat. Exp. Brain Res. 85: $577-586$.

Li, X.F., R.G. Phillips, and J.E. LeDoux. 1995. NMDA and non-NMDA receptors contribute to synaptic transmission between the medial geniculate body and the lateral nucleus of the amygdala. Exp. Brain Res. 105: 87-100.

Malenka, R.C. and R.A. Nicoll. 1993. NMDA-receptordependent synaptic plasticity: Multiple forms and mechanisms. Trends Neurosci. 16: 521-527.

Maren, S. and M.S. Fanselow. 1995. Synaptic plasticity in the basolateral amygdala induced by hippocampal formation stimulation in vivo. J. Neurosci. 15: 7548-7564.

Mascagni, F., A.J. McDonald, and J.R. Coleman. 1993. Corticoamygdaloid and corticocortical projections of the rat temporal cortex: A phaseoulus vulgaris leucoagglutinin study. Neuroscience 57: 697-715.

Mello, L.E.A.M., A.M. Tan, and D.M. Finch. 1992. Convergence of projections from the rat hippocampal formation, medial geniculate and basal forebrain onto single amygdaloid neurons: An in vivo extra- and intracellular electrophysiological study. Brain Res. 587: 24-40.

Miserendino, M.J.D., C.B. Sananes, K.R. Melia, and M. Davis. 1990. Blocking of acquisition but not expression of conditioned fear-potentiated startle by NMDA antagonists in the amygdala. Nature 345: 716-718.

O'Donnell, P. and A.A. Grace. 1995. Synaptic interactions among excitatory afferents to nucleus accumbens neurons: Hippocampal gating of prefrontal cortical input. J. Neurosci. 15: $3622-3639$.

Paré, D., H.C. Pape, and J. Dong. 1995. Bursting and oscillating neurons of the cat basolateral amygdaloid complex in vivo: Electrophysiological properties and morphological features. I. Neurophysiol. 74: 1179-1191.

Quirk, G.J., J.C. Repa, and J.E. LeDoux. 1995. Fear conditioning enhances short-latency auditory responses of lateral amygdala neurons: Parallel recordings in the freely behaving rat. Neuron 15: 1029-1039.

Quirk, G.J., J.L. Armong, J.C. Repa, X.-F. Li, and J.E. LeDoux. 1996. Emotional memory: A search for sites of plasticity. Cold Spring Harbor Symp. Quant. Bio. 61: (in press).

Rainnie, D.G., E.K. Asprodini, and P. Shinnick-Gallagher. 1991. Excitatory transmission in the basolateral amygdala. J. Neurophysiol. 66: 986-998.

1991b. Inhibitory transmission in the basolateral amygdala. I. Neurophysiol. 66: 999-1009.

1993. Intracellular recordings from morphologically identified neurons of the basolateral amygdala. $).$ Neurophysiol. 69: 1350-1362.
Rogan, M.T. and J.E. LeĐoux. 1995. LTP is accompanied by commensurate enhancement of auditory-evoked responses in a fear conditioning circuit. Neuron 15: 127-136. 1996. Emotion: Systems, cells, synaptic plasticity. Cell 85: 469-475.

Romanski, L.M. and J.E. LeDoux. 1993b. Information cascade from primary auditory cortex to the amygdala: Corticocortical and corticoamygdaloid projections of temporal cortex in the rat. Cereb. Cortex 3: $515-532$.

1993a. Organization of rodent auditory cortex: Anterograde transport of PHA-L from MGv to temporal neocortex. Cereb. Cortex 3: 499-514.

Romanski, L.M., M.C. Clugnet, F. Bordi, and J.E. LeDoux. 1993. Somatosensory and auditory convergence in the lateral nucleus of the amygdala. Behav. Neurosci. 107: 444-450.

Sugimori, M., R.J. Preston, and S.T. Kitai. 1978. Response properties and electrical constants of caudate nucleus neurons in the cat. J. Neurophysiol. 41: 1662-1675.

Sugita, S., E. Tanaka, and R.A. North. 1993. Membrane properties and synaptic potentials of three types of neurone in rat lateral amygdala. J. Neurophysiol. 460: 705-718.

Thomson, A.M. 1986. A magnesium-sensitive post-synaptic potential in rat cerebral cortex resembles neuronal responses to $\mathrm{N}$-methylaspartate. J. Physiol. 370: 531-549.

Thomson, A.M., D. Girdlestone, and D.C. West. 1989. A local circuit neocortical synapse that operates via both NMDA and non-NMDA receptors. Br. J. Pharmacol. 96: 406-408.

Turner, B.H., M. Mishkin, and M. Knapp. 1980. Organization of the amygdalopetal projections from modality-specific cortical association areas in the monkey. J. Comp. Neurol. 191: 515-543.

Xiang, Z., A.C. Greenwood, E.W. Kairiss, and T.H. Brown. 1994. Quantal mechanism of long-term potentiation in hippocampal mossy-fiber synapses. J. Neurophysiol. 71: 2552-2556.

Washburn, M.S. and H.C. Moises. 1992. Electrophysiological and morphological properties of rat basolateral amygdaloid neurons in vitro. 1. Neurosci. 12: $4066-4079$.

Received June 25, 1996; accepted in revised form September $11,1996$.

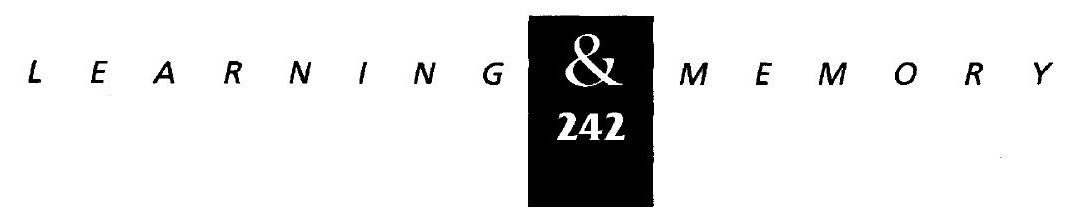



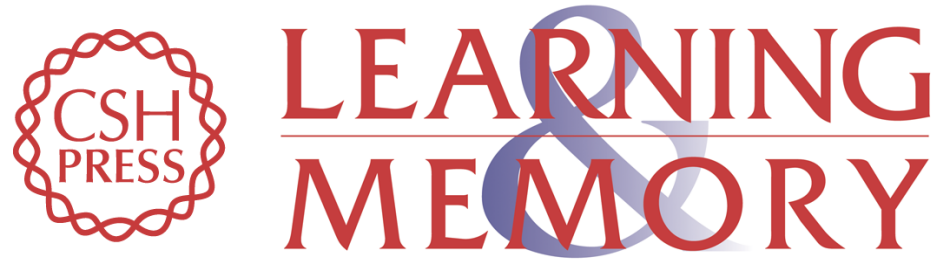

Convergent but temporally separated inputs to lateral amygdala neurons from the auditory thalamus and auditory cortex use different postsynaptic receptors: in vivo intracellular and extracellular recordings in fear conditioning pathways.

X F Li, G E Stutzmann and J E LeDoux

Learn. Mem. 1996, 3:

References This article cites 51 articles, 9 of which can be accessed free at: http://learnmem.cshlp.org/content/3/2-3/229.full.html\#ref-list-1

License

Email Alerting

Receive free email alerts when new articles cite this article - sign up in the box at the Service top right corner of the article or click here. 